\title{
New Ideas and Application of the Construction of Academic Atmosphere Based on Group Counseling and Coaching Technology
}

\author{
Junzheng Wang ${ }^{1, a}$ and Guixue $\mathrm{Hu}^{2, b^{*}}$ \\ ${ }^{1,2}$ College of Engineering and Technology, Jilin Agricultural University,Xincheng Street 2888, \\ Changchun, Jilin Province 130118, PR China \\ a595845966@ @q.com, buixue1964@126.com \\ ${ }^{*}$ The corresponding author
}

Keywords: Group counseling; Coaching technology; Common promotion; Style of study

\begin{abstract}
. group counseling, from "group counseling", refers to the group counseling in a team environment is a kind of psychological counseling, with the team and the collective power to help themselves throughout the process.Coaching technology, translated from "coaching", is the current relatively new means of human resources development, in the enterprise management and training more and more attention and favor of managers, coaching technology is focused on people-oriented, focus on inspiration and inspiration to achieve personal and Team win-win situation. After a period of exploration and research, group counseling technology and coaching technology in the common advancement of the school class construction has played a good work results.
\end{abstract}

\section{In the Current Problems in the Construction of Class Style in Colleges and Universities}

Lack of Self-learning Motivation, Lack of Ability to Adapt. Before entering the university, students of high school life is basically a three-point line of life, are basically boring all-weather, full-time study state.Currently, the University emphasizes the emphasis is to develop students' self-learning ability, will not "force" the students to learn. A considerable part of the students into the university, can not be better adapted to the university to study life, the lack of teachers after strict management, like a kite off the line, feeling nothing, lack of learning goals and motivation, can not be well adapted Self-learning atmosphere. Do not know "why learn, learn what, how to learn," the fundamental proposition of this self-learning.

Speculative Phenomenon Still Exists, Discipline Awareness to be Strengthened. I do not know since when, a considerable part of the students to reach 60 points as the ultimate goal. Usually do not listen to class, do not take notes, near the final exam, the surprise review of a period of time is very common. What is more, a small number of students exist late leave early, absenteeism uncivilized phenomenon. At the same time, there are a very small number of students, usually do not review, do not work hard, try to cheat when the phenomenon, of course, this is only a very small part.

Self-regulation Ability is Lacking, Mental Health Education System Need to be Improved. I will each school year with the students with a talk and talk. Through the exchange found that some students unhappy results, mainly the lack of good self-regulation ability. There are many times the students can not withstand the temptation of the outside world, and some often out of Internet cafes, addicted to the game, deserted school, can not correctly handle the relationship between learning and entertainment; some because of family reasons, emotional reasons, friends and other external factors Can not be very good into the learning state, academic performance can not reach the ideal state, the ability of students to self-regulation is limited, college mental health education system need to be further improved.

\section{The Application of Group Counseling in the Construction of Class Style of Study}

Group Counseling Theory Analysis. Group counseling is a form and method of providing psychological assistance and assistance in group atmosphere and circumstances. Group counseling 
is a group carrier. By mobilizing the enthusiasm of group members, group members are allowed to communicate with each other, through certain forms of activities and Interpersonal help interaction, mutual induction support, encouragement, group members to discuss issues of mutual concern, and ultimately the formation of group consensus and goals. Through group counseling activities, members of the group in the atmosphere of mutual influence, common development, common progress, common learning and common improvement. Group counseling is generally hosted by 1-2 counselors, according to different circumstances, tutors can reach a dozen people, the number of activities is generally several times to ten times. Group counseling needs to have specific activities, to establish a corresponding activity group, through the exchange and help, active atmosphere, through the activities of the development, to find the problem, analyze the problem, solve the problem, and ultimately to form an assessment report.

Feasibility Analysis of Group Counseling Applied to Class Style Construction. The stability of the implementation of the main body. Take the author's college as an example, starting from the freshman after graduation, until the university graduate, the entire class of the main staff will not be a big change, only some students will turn professional, or drop out, drop out, leave and other special circumstances, There will be a very small range of personnel changes, does not affect the stability and integrity of the class. At the same time, the class student cadre and student party members in the class construction also played the mainstay of the role of class cohesion to further enhance the implementation of group counseling the stability of the subject is self-evident.

Instruct the teacher's fixation. Recently, the CPC Central Committee and the State Council issued "the Opinions on Strengthening and Reforming Ideological and Political Work in Colleges and Universities under the New Situation"made it clear that teachers and special forces should be strengthened. The formation of a full-time-based, special combination, the number of adequate. Excellent quality of work.[1]In the current good environment, colleges and universities pay more and more attention to ideological and political education, each class has designated full-time counselors to the author's school, for example, the school attaches great importance to students ideological and political education, to promote each counselor With a full four years of students, under normal circumstances, from the new students to graduate is the counselor band, effectively avoid the new and old counselors in the transfer work in the existence of "work dead zone" and "work blindness" At the same time, the school also for each class selected a part-time teacher, in the construction of style of study, employment guidance and other aspects of the class for students. In this way, students in the full period of college, are a fixed counselor and part-time teacher, in the group counseling activities, with significant operability.

Vector diversity of group counseling techniques. First, you can use group counseling skills in moral education. The teaching of the current moral education course is mainly based on the preaching, there is not much innovation at all, in the course of the course is sometimes inevitably look more rigid and boring, students of class enthusiasm and interest is difficult to effectively drive up, want to Good moral education course is not an easy thing. The use of group counseling technology to the process of moral education in order to increase the classroom interaction, fun, the scene, to enhance the freshness of the classroom, to stimulate students interest in class, both to ensure good teaching results, but also to create Good style of study, class style.Second, students can be used in student cadres and student group counseling skills. These groups are positive, upward, and shapeable. Through the group counseling technology, both students can cultivate the business skills, improve the overall quality of students, but also can enhance the enthusiasm of students, work enthusiasm. If you fully use the enthusiasm of these advanced students, each "advanced" student to help a certain number of "backward" students, can play a point with a good effect, to create a good learning atmosphere.

The Application of Coaching Skills in Group Counseling. The four concepts of coaching technology: first, everyone is "okay", for each person are highly trusted and trusted; second, everyone has to solve the relevant problems of the necessary resources and conditions; Third, each behavior and action behind the positive significance; Fourth, everyone is have the ability to make a change. 
The feasibility of coaching skills in group counseling. In the course of the construction of the class style of study, the "leader" is the class counselor, but because the counselor's daily affairs work more, energy is limited, can not guarantee one-on-one counseling and help, group counseling And students.However, the effect of group counseling, the number of student benefits, after the group counseling, students will continue in accordance with the requirements of the group counseling activities and action, which requires counselors to establish a sound, follow-up support And accountability systems. This support system and accountability system based on group counseling is part of the coaching skills. It can be seen that the feasibility of coaching technology in group counseling is still very obvious, the two can be integrated together to promote the construction of class style of study.

the Application of Coaching Skills in the Construction of Class Style of Study. The connotation of coaching technology. Coaching technology both with the traditional management methods similar to the foundation and consensus, but also its unique and unique principles and methods.[2]Coach technology is mainly to support and encourage the coaches to fully develop a process, coaches through a certain way to identify the coach's mental way and model to help coaches find their own resources, to stimulate their own potential process, Guide the coaches to have the potential to find their own problems, to solve their own problems, to encourage coaches to take appropriate effective action to achieve the self-realization of the whole process.

Coaching technology in the construction of class style of attention. First,we should pay attention to the knowledge level of learning and accumulation.Questioning and listening are two core skills in coaching skills. Into the student's heart, a very important way is to put themselves in to listen to. Every time you listen and ask questions, will let us more in-depth grasp of the student's learning situation, the class style of study. At the same time, in the process of listening, we should strive to explore their needs, grasp the key factors in the construction of class style of study, class classes to provide support.

Second, innovative work ideas. To guide students to have confidence in their own, confident. Guide students to believe that they are the experts to solve their own problems. To change the past, the simple management of the work model, to innovate the work of thinking, the coach will be introduced into the construction of style of study, so that students in the class construction, self-management, self-service, self-promotion, to stimulate individual in the construction of the potential.

Third, let the students down to earth to participate in the coach technology. Not only to enable students to establish a reasonable, achievable goals, understand what they want to achieve what purpose, want to achieve what purpose, better guide students to establish their own goals with practical action to implement, and the implementation of goals, Down, turn your goals into a concrete, continuous action. Guide students to establish reasonable measures and heart steps.

Fourth, the establishment of support and accountability systems. In this process, to ensure that students have sustained action and substantial growth, to guide students in the process of achieving the goal, to think: if not in accordance with pre-designed action goals to practice, how to do their own, how to make up. At the same time, as a coach, to go digging and research, why the coach did not follow the pre-designed program to implement, to implement, how to ensure that coaches can really let the program of action to take root.

In short, the group counseling technology and coaching technology are now a new groundbreaking technology, the organic combination of the two can be in the class construction process to play a role can not be underestimated, and even in the ideological and political education of college students can Play a unique technical advantages for our students to better serve the students healthy growth, talent to provide a strong support.

\section{References}

[1] The CPC Central Committee and State Council on strengthening and transforming the new situation under the ideological and political work of the views .2017. 
[2] L.L Zhang, Q Huai, Coaching technology in the counselor's work in the application of thinking [J]. Higher Education Journal, 2015 (22). 